\title{
COnstitucionalidade DAs CONVALIDAÇÕES DE INCENTIVOS FisCAIS ACORDADAS ENTRE OS ESTADOS
}

\author{
José Roberto Afonso* \\ Luciano Felicio Fuck** \\ Daniel Corrêa Szelbracikowski***
}

1 Introdução. 2 Distinguishing entre o debatido no re n. ${ }^{\circ} 851.421$ (caso paradigma) e o decidido na adi 2906 e nos res n. ${ }^{\text {ss }} 390.840 / \mathrm{mg}, 357.950 / \mathrm{rs}$, $358.273 /$ rs, 346.084/pr. $3 \mathrm{O}$ federalismo de cooperação e a proteção à confiança. 4 Superação de inconstitucionalidade formal e diálogo institucional. 5 Conclusão. Referências.

\section{RESUMO}

O Supremo Tribunal Federal julgará se é possível perdoar créditos tributários decorrentes de incentivos concedidos unilateralmente pelos Estados e pelo Distrito Federal, no passado, se houver posterior concordância do CONFAZ sobre a matéria. Considerando que a inconstitucionalidade formal é sanável, legislação superveniente que tenha obedecido ao procedimento previsto constitucionalmente não poderia ser taxada de inconstitucional em razão de vícios de forma presentes nas legislações anteriores. Não se trata de modular a eficácia das leis anteriormente declaradas inconstitucionais. As leis mais recentes, com amparo no princípio da separação dos poderes e no pacto federativo, tratam de outra matéria, isto é, do tratamento normativo dos créditos tributários nascidos em decorrência da utilização dos benefícios fiscais declarados inconstitucionais. Impedir a referida remissão retiraria dos

* Economista e contabilista; professor do programa de Mestrado do Instituto de Direito Público (IDP); pesquisador do Instituto Brasileiro de Economia da Fundação Getúlio Vargas (IBRE/FGV). Doutor em Desenvolvimento Econômico pela Universidade Estadual de Campinas (UNICAMP) e mestre em Economia Industrial pela Universidade Federal do Rio de Janeiro (UFRJ). Lattes: < http://lattes.cnpq.br/6297334841318823> . E-mail: <zerboerto@joserobertoafonso.com.br>.

** Professor do mestrado e da graduação no Instituto Brasiliense de Direito Público (IDP). Mestre em Direito (LL.M. Eur.) pela Universidade de Munique (Ludwig-Maximilians-Universität - LMU). Doutor em Direito pela Universidade de São Paulo (USP). Chefe de Gabinete de Ministro no Supremo Tribunal Federal. Lattes: <http://buscatextual.cnpq.br/ buscatextual/visualizacv.do?id=K4217853Y5>. E-mail: <lucianofelicio@gmail.com>.

***Advogado. Professor da Especialização em Direito Tributário no Instituto Brasileiro de Estudos Tributários (IBET). Especialista em Direito Tributário pelo IBET. Mestrando pelo Instituto Brasiliense de Direito Público (IDP). Bacharel em Direito pela Universidade de Brasília (UnB). Lattes: <http://lattes.cnpq.br/4793388135441341>. E-mail: <daniel.correa@advds.com.br>. 
Estados que compõem a Federação um dos instrumentos que, no contexto do federalismo de coordenação e de cooperação, possibilitam a negociação em torno dos problemas relativos à Guerra Fiscal em busca do bem-estar coletivo e em respeito às expectativas dos contribuintes.

Palavras-chave: Supremo Tribunal Federal. Guerra Fiscal. Remissão. CONFAZ. Pacto Federativo. Federalismo. Cooperação. Segurança jurídica.

\section{INTRODUÇÃO}

O Supremo Tribunal Federal apreciará a constitucionalidade dos Estados e do Distrito Federal, com expressa autorização do Conselho Nacional de Política Fazendária (CONFAZ), editarem lei para perdoar dívidas tributárias decorrentes de incentivos fiscais ${ }^{1}$ concedidos, no passado, sem a aludida autorização dos demais entes federativos. O reconhecimento da relevância do tema ocorreu nos autos do Recurso Extraordinário (RE) n. ${ }^{\circ} 851.421 / \mathrm{DF}$, que ainda será analisado pelo Plenário do Tribunal, sob a relatoria do Ministro Marco Aurélio Mello.

O caso concreto trata da constitucionalidade da Lei Distrital n. ${ }^{\circ}$ 4.732/11, que suspendeu a exigibilidade e concedeu a remissão de créditos de ICMS concedidos no âmbito do "Programa Pró-DF" e dos "Termos de Acordo de Regime Especial" - TAREs, a partir da autorização dada pelo CONFAZ por meio dos Convênios n. ${ }^{\text {os }} 84 / 2011$ e 86/2011. ${ }^{2}$ Os aludidos benefícios haviam sido declarados inconstitucionais, no passado, pois foram concedidos pelo Distrito Federal sem a autorização dos demais Estados, por meio de Convênio do CONFAZ, em afronta ao disposto no art. 155, $\S 2^{\circ}$, XII, 'g', da Constituição Federal de $1988(\mathrm{CF} / 88)$ c/c os arts. $1^{\circ}$ e $2^{\circ}, \S^{\circ}$, da Lei Complementar (LC) n. ${ }^{\circ} 24 / 75 .{ }^{3}$

Ao reconhecer a relevância da questão, o Relator do recurso, E. Ministro Marco Aurélio, assim, delimitou a tese:

A controvérsia, passível de repetição em inúmeros casos, está em saber se podem os Estados e o Distrito Federal, mediante consenso alcançado no âmbito do Confaz, perdoar dívidas tributárias surgidas em decorrência do gozo de benefícios fiscais implementados no âmbito da chamada guerra fiscal do ICMS, assentados inconstitucionais pelo STF. ${ }^{4}$

De fato, a questão é relevante sob todos os aspectos pelos quais se analisa:

a) juridicamente, pois em jogo:

- a possibilidade de serem remidos os débitos tributários de ICMS decorrentes da fruição de benefícios fiscais concedidos unilateralmente por algum Estado da Federação, desde que após concordância dos demais Estados e edição de lei específica pelo ente da federação responsável pela instituição 
e cobrança do imposto, nos termos dos arts. $155, \S 2^{\circ}$, XII, 'g', da CF/88 e arts. $1^{\circ}, 2^{\circ}, \S 2^{\circ}$, e 10 da LC n. ${ }^{\circ} 24 / 75$ e;

- a autonomia dos entes federativos para, em consenso e em atenção ao pacto federativo e à separação dos poderes $\left(\operatorname{arts.} 1^{\circ}\right.$, caput, $2^{\circ}$ e $60, \S 4^{\circ}$, I, da $\mathrm{CF} / 88$ ), deliberarem cooperativamente acerca dos problemas relacionados à denominada Guerra Fiscal; ${ }^{5}$

b) economicamente, pois, sem a aludida remissão, as empresas que confiaram nos incentivos concedidos pelo Estado precisariam arcar com a diferença de tributos entre o que seria devido sem o incentivo e o que foi pago com o incentivo, em prejuízo aos princípios da moralidade e confiança em face dos atos do Poder Público (arts. $5^{\circ}$, caput, e 37 da CF/88); e

c) socialmente, pois os incentivos fiscais geraram benefícios aos locais em que aplicados, o que o Confaz não desconsiderou ao permitir a remissão, nem o Judiciário deverá desconsiderar ao apreciar o mérito da questão.

Chama a atenção, entretanto, o entendimento manifestado pelo Relator ao atribuir efeito suspensivo ao recurso extraordinário do Ministério Público do Distrito Federal e, antecipando o julgamento de mérito do recurso, reconhecer "flagrante inconstitucionalidade da Lei Distrital n. ${ }^{\circ}$ 4.732, de 2011 (...) vindo a tornar sem efetividade o comando constitucional do artigo 155, $\S 2^{\circ}$, inciso XII, alínea "g", como por afrontar a autoridade interpretativa e a decisória do Supremo". ${ }^{\circ}$

Esse pré-julgamento "monocrático", ocorrido quando da apreciação da AC n. ${ }^{\circ} 3802 / \mathrm{DF}$, ancorou-se, em síntese, nos seguintes fundamentos:

a) essa espécie de convalidação de incentivos fiscais já fora julgada inconstitucional pelo Supremo na Ação Direta de Inconstitucionalidade (ADI) n. ${ }^{\circ}$ 2906/RJ; e

b) o vício originário não seria superado com a edição de Convênio do CONFAZ, "pois esses atos normativos interestaduais não são capazes de tornar válidas normas nascidas inconstitucionais", 7 conforme alegadamente definido pelo STF nos REs n. ${ }^{\circ}$ 390.840/MG, 357.950/RS, 358.273/RS, 346.084/PR.

Em razão da relevância do tema, este artigo pretende verificar em que medida são aplicáveis à hipótese os julgados referidos na $\mathrm{AC} \mathrm{n} .^{\circ} 3802$ / DF, assim como investigar a função do Supremo Tribunal Federal, como Tribunal da Federação, em face de atos que exprimem a autonomia e a cooperação das unidades parciais de poder para a resolução de alguns dos efeitos deletérios da denominada Guerra Fiscal dos Estados - que, aliás, não constitui um caso único brasileiro, mas é um fenômeno recorrente em países federativos, sobretudo aqueles com maior autonomia dos governos regionais e locais. ${ }^{8}$ 


\section{DISTINGUISHING ENTRE O DEBATIDO NO RE N. ${ }^{\circ} 851.421$ (CASO PARADIGMA) E O DECIDIDO NA ADI 2906 E NOS RES N³90.840/ MG, 357.950/RS, 358.273/RS, 346.084/PR}

Para conceder a liminar que atribuiu efeito suspensivo ao RE de repercussão geral em epígrafe, o Relator afirmou, de início, que "o Supremo já apreciou caso similar, tendo afastado prática legislativa da espécie". Referia-se à ADI n. ${ }^{\circ} 2.906 / \mathrm{RJ}$, em que

esteve envolvida lei do Estado do Rio de Janeiro por meio da qual foi dispensado o pagamento de multa e de juros de mora relativos ao Imposto sobre Circulação de Mercadorias e Serviços - ICMS, que passou a ser cobrado em virtude da suspensão de benefício fiscal por decisão do próprio Tribunal - Medida Cautelar na Ação Direta de Inconstitucionalidade n. ${ }^{\circ} 1.179 /$ SP, da relatoria do ministro Carlos Velloso. Por unanimidade, o Pleno assentou tratar-se de "drible" à liminar deferida. ${ }^{9}$

Ocorre que o objeto daquela ADI não se confunde com o debatido na repercussão em tela.

Com efeito, naquele caso, o Supremo havia declarado a inconstitucionalidade de uma lei fluminense que concedera prazo especial para pagamento do ICMS sem a prévia autorização do CONFAZ. Na sequência, novamente sem amparo em convênio do CONFAZ, o Estado do RJ editou uma lei concedendo parcelamento dos débitos tributários e dispensando os contribuintes do pagamento de multa e de juros de mora sobre aqueles valores. Essa última lei é que foi questionada na ADI 2.906/RJ: o STF a declarou inconstitucional os benefícios fiscais, não em razão do mérito relativo à remissão e à concessão de carências e de parcelamentos, mas "porquanto também veiculados sem prévio acordo interestadual", conforme constou do pedido do autor da ação direta (Governo do Estado de São Paulo), retratado no relatório do respectivo acórdão. ${ }^{10}$

$\mathrm{Na}$ situação em que reconhecida a repercussão geral, embora o STF também tenha declarado inconstitucionais as leis que instituíram os benefícios originais de ICMS por não ter havido o procedimento exigido constitucionalmente para a sua instituição, a remissão posteriormente concedida obedeceu à risca o rito previsto legal e constitucionalmente, pois:

a) teve amparo em Convênio unânime do CONFAZ e;

b) foi concedida por lei específica da unidade da federação a que se reportava.

Quer dizer, enquanto, na hipótese julgada na ADI n. ${ }^{\circ} 2.906$, houve nova burla à sistemática prevista no art. $155, \S 2^{\circ}$, XII, 'g', da CF/88, na situação em testilha, a referida norma foi observada, o que torna o decidido naquele julgado inaplicável ao caso.

Vejamos, por outro lado, se o decidido nos REs n. ${ }^{\text {os }} 390.840 / \mathrm{MG}, 357.950 /$ RS, 358.273/RS, 346.084/PR seria aplicável à espécie. Nos aludidos recursos, 
o STF apreciou a constitucionalidade da Lei n. ${ }^{\circ}$ 9.718/98, no que ampliou a base de cálculo da COFINS prevista no texto Constitucional para abranger a totalidade das receitas auferidas pelas pessoas jurídicas. Na época da edição da referida lei, a norma do art. 195, I, 'b', da Carta Maior previa a imposição tributária apenas sobre o faturamento. O STF analisou, então, se seria possível a constitucionalidade superveniente daquela lei, considerando que, após sua instituição, fora promulgada emenda constitucional para possibilitar a incidência da contribuição, também, sobre a receita.

Corretamente entendeu o STF pela impossibilidade de declaração de constitucionalidade superveniente. Segundo o Ministro Marco Aurélio, "Descabe, também, partir para o que seria a repristinação, a constitucionalização de diploma que, ao nascer, mostrou-se em conflito com a Constituição Federal". ${ }^{11}$ Em interpretação livre daquele acórdão, ficou consignado que a inconstitucionalidade deveria ser verificada no momento da edição da lei e seria insanável. Retroagiria até o nascedouro da norma, ainda que houvesse modificação posterior da Constituição que possibilitasse, dali para frente, a instituição da regra que outrora fora considerada inconstitucional.

Esse entendimento, entretanto, não conflita com o procedimento realizado pelo Distrito Federal na hipótese, por duas razões:

a) primeiro, porque não se discute a constitucionalidade superveniente das leis distritais n. ${ }^{\text {os }} 2381 / 99 ; 2483 / 99$ e 4.160/08, que introduziram os benefícios fiscais de ICMS (TAREs e Pró-DF). Essa discussão - constitucionalidade superveniente - somente haveria se o texto da Constituição tivesse sido modificado para permitir a concessão de incentivos unilateralmente pelos Estados da Federação e, mesmo assim, estaria fadada ao fracasso em atenção ao precedente supracitado. Não há dúvida de que aquelas leis foram elaboradas em desatenção ao procedimento previsto nos textos legal e constitucional, de modo que não poderiam ser um caso de repristinação;

b) segundo, porque o que se debate é a possibilidade de o Estado, obedecendo ao procedimento constitucional, instituir novas leis para tentar solucionar os problemas - atos concretos - decorrentes da inconstitucionalidade dos atos legislativos anteriores.

Sob esses aspectos, há de se observar que as recentes leis do Distrito Federal não concederam aqueles mesmos incentivos que foram instituídos, no passado, sem a aprovação do CONFAZ. Apenas permitiram a remissão de atos concretos consubstanciados em créditos tributários nascidos em decorrência da inconstitucionalidade daquela legislação, sob a condição de que aquele ente da Federação não viesse mais a legislar em desconformidade com a Constituição.

Não se discute, portanto, a constitucionalidade superveniente dos diplomas originários que concederam incentivos fiscais sem o respeito ao procedimento constitucional próprio (Leis Distritais n. ${ }^{\text {ss }} 2381 / 99 ; 2483 / 99$ e 4.160/08), mas a legitimidade de leis posteriores (Leis Distritais n. ${ }^{\text {os }} 4.732 / 11$ e 4.969/12), 
editadas após a regular concordância do CONFAZ (Convênios n.os 84/2011 e 86/2011), para sanar efeitos concretos decorrentes da inconstitucionalidade daquelas - o que não se contesta.

Apenas essas considerações já afastariam a aplicação do decidido nos aludidos REs n. ${ }^{\text {s } 390.840 / M G, ~ 357.950 / R S, ~ 358.273 / R S, ~ 346.084 / P R ~ a ̀ ~ h i p o ́ t e s e . ~}$ Há mais, entretanto.

Nos julgados citados, o STF estava a tratar de vício de inconstitucionalidade material, enquanto, na espécie, a questão gravita em torno de haver, ou não, inconstitucionalidade formal, por vício na formação do ato normativo.

Ao distinguir vícios formais e materiais de inconstitucionalidade, CANOTILHO anota que, "na hipótese de inconstitucionalidade formal, viciado é o acto, nos seus pressupostos, no seu procedimento de formação, na sua forma final". ${ }^{12}$ Do mesmo modo, MENDES observa que o parâmetro de distinção entre as espécies de inconstitucionalidade está na "origem do defeito", explicitando que "os vícios formais traduzem defeito de formação do ato normativo, pela inobservância do princípio de ordem técnica ou procedimental ou pela violação de regras de competência". ${ }^{13}$

Ora, nos precedentes citados pela decisão proferida pelo Ministro Marco Aurélio Mello, o STF entendeu que, ao prever a incidência da COFINS sobre a receita e não sobre o faturamento, a Lei n. ${ }^{\circ}$ 9.718/98 alargou o campo de imposição tributária previsto pela Constituição Federal no art. 195, I, 'b', em sua redação originária. Ou seja, tratou-se de típica hipótese de inconstitucionalidade material.

Na situação em análise, entretanto, a causa da declaração de inconstitucionalidade dos incentivos concedidos pelo Distrito Federal, no passado, era de índole formal, porque não fora atendido o procedimento ${ }^{14}$ previsto constitucionalmente para a concessão dos benefícios, isto é, a celebração de Convênio no âmbito do CONFAZ.

De fato, em momento algum, o STF adentrou o mérito dos incentivos fiscais para saber se esses eram, ou não, inconstitucionais, por eventualmente afrontar o campo da materialidade impositiva relacionada ao ICMS. Apenas disse que os benefícios não poderiam ser instituídos unilateralmente, sem prévia deliberação do CONFAZ, ou seja, em função de um vício de procedimento.

Daí porque, se outros veículos introdutores de normas obedeceram ao procedimento constitucionalmente previsto, não se poderia imputá-los a inconstitucionalidade verificada nas normas anteriores que não obedeceram ao disposto no art. $155, \S 2^{\circ}$, XII, 'g', da CF/88.

Não se trata de modular a eficácia das leis anteriormente declaradas inconstitucionais. Os efeitos da declaração de inconstitucionalidade daqueles diplomas normativos ocorreram, tanto que as empresas e os responsáveis solidários foram, em muitos casos, condenados a pagar a diferença de ICMS em razão da fruição dos benefícios inconstitucionais. 
As leis mais recentes, com amparo no princípio da separação dos poderes e no pacto federativo (arts. $1^{\circ}$ e $2^{\circ} \mathrm{da} C F / 88$ ), possibilitaram apenas a mitigação de alguns dos efeitos concretos e deletérios decorrentes dos atos legislativos anteriores, mediante a realização de remissão condicionada de créditos tributários.

Em síntese, as leis distritais, em discussão no processo de repercussão geral, não reinstituíram os incentivos inconstitucionais, embora pudessem ter feito isso, já que o STF nunca adentrou a constitucionalidade material daqueles benefícios. ${ }^{15}$ Esses recentes diplomas normativos apenas permitiram que determinados atos concretos decorrentes da edição de normas inconstitucionais pudessem ser perdoados com supedâneo no princípio da confiança dos administrados no Poder Público e na competência tributária do Distrito Federal e do Confaz para legislar sobre ICMS.

\section{O FEDERALISMO DE COOPERAÇÃO E A PROTEÇÃO À CON- FIANÇA}

A forma federativa do Estado, cláusula constitucional imutável, determina que as decisões tomadas em conjunto pelas unidades federadas sejam respeitadas, inclusive pelo Judiciário (art. $2^{\circ}$ da $\mathrm{CF} / 88$ ), se não houver transgressão ao ordenamento jurídico.

Embora o sistema federativo brasileiro possua certas características do federalismo dualista (ou de competição), "na medida em que estabelece campos específicos de atuação para cada uma das unidades, delimitando a área de atuação da União, dos Estados-membros e dos Municípios", ${ }^{16}$ define-se, também, pela adoção de técnicas do federalismo de cooperação, ${ }^{17}$ "caracterizado pela colaboração entre União e Estados com vista a resolver os problemas econômicos e sociais". ${ }^{18}$

Dessa forma, considerando que o desenvolvimento do federalismo de cooperação implica a "coordenação e cooperação entre União e Estados (...), tornando o federalismo um instrumento da promoção do bem-estar coletivo", ${ }^{19}$ as decisões unânimes tomadas pelos Estados não podem ser desconsideradas pelo Tribunal da Federação. ${ }^{20}$

Trata-se, afinal, da autonomia dos entes federativos, que, apesar de limitada e circunscrita à atribuição de competências constitucionais, constitui o ponto nodal para o equilíbrio da Federação. ${ }^{21}$ Nesse sentido,

impõe-se (...) para coroamento e consolidação do sistema, promover a convocação da autonomia para colaborar, dentro de seu ordenamento, na tarefa de organização do federalismo cooperativo. ${ }^{22}$

Na situação objeto de análise, os Convênios do Confaz (Executivo) e as Leis Distritais (Legislativo) dispuseram sobre matéria que estava no âmbito de suas competências, visto que a outorga de remissão mediante condição é expressamente admitida pelo art. 10 da Lei Complementar n. ${ }^{\circ}$ 24/1975, norma 
especial que rege a concessão de incentivos e de benefícios do ICMS, nos termos dos arts. $150, \S 6^{\circ}$, c/c 155, $\S 2^{\circ}$, XII, “g”, da CF/88.

Daí o motivo de impedir essa possibilidade de remissão significaria retirar dos Estados que compõem a Federação um dos instrumentos que, no contexto do federalismo de cooperação, possibilitam a negociação em torno dos problemas relativos à Guerra Fiscal.

Em outras palavras, fragilizaria a atividade política desenvolvida pelos Estados que têm na remissão uma de suas bandeiras para tentar amenizar os efeitos perversos da denominada "Guerra Fiscal", conforme se verifica de projeto de lei complementar que está em discussão no Congresso Nacional sobre o tema. ${ }^{23}$

Aliás, o próprio termo "Guerra Fiscal” só tem sentido quando há um conflito entre os Estados, o que fica afastado na hipótese em que todos concordam com a concessão de remissão de créditos tributários sob a condição de que não sejam instituídos novos benefícios de forma unilateral.

À parte, é bom qualificar que o conflito surge no caso do ICMS em torno das operações interestaduais. Isso ocorre quando um Estado concede, de forma disfarçada, um benefício sobre uma venda realizada para outro Estado, reduzindo (de alguma forma e por subterfúgio que foge ao CONFAZ) o débito sobre tal saída. Como a mercadoria chega ao Estado de destino com uma nota fiscal em que acusa o imposto que normalmente seria devido (e não o que foi efetivamente pago) e assim gera um crédito ao contribuinte que adquiriu tal bem, o custo do benefício fiscal acaba sendo suportado direta e integralmente pelo fisco estadual de destino.

A análise anterior também merece uma leitura pela outra ótica - a dos contribuintes. A decisão de política tributária de ICMS de um Estado, cujos efeitos são transferidos aos Estados destinatários das mercadorias subsidiadas via alíquota interestadual, pode afetar a economia e a competitividade das empresas de todos os demais Estados. Por isso, a unanimidade se fez necessária no contexto da criação do ICMS, em que os convênios tinham força de lei - eram impositivos ${ }^{24}$ e não autorizativos -, sendo ainda um critério válido, ${ }^{25}$ porque o imposto, gerido por todos, tem sua receita compartilhada quando ocorrem transações interestaduais. Isso porque uma das formas de incentivos do ICMS (e a única que importa para a chamada guerra fiscal) é a redução da alíquota interestadual.

Este debate também mostra que a Guerra Fiscal extrapola a fronteira de matéria tributária e abrange a própria concorrência. A um contribuinte não basta apenas buscar e conseguir um incentivo fiscal. Ele necessariamente precisa tentar saber que benefícios, iguais ou assemelhados, seus concorrentes domésticos e diretos já lograram obter ou podem vir a receber. Ou seja, não importa a um empreendedor apenas ser beneficiário de um incentivo fiscal, mas também importa aos seus negócios conhecer os benefícios igualmente concedidos aqueles aos seus concorrentes. 
Essa questão concorrencial está na origem da Guerra Fiscal do ICMS porque, como dito, não importa a um contribuinte apenas ganhar um benefício, mas o ideal é que seu concorrente não receba igual incentivo ou, se receber, ideal que seja proporcionalmente inferior ao seu. A mesma questão surge quando se tratar de eventualmente da reversão da mesma Guerra Fiscal. Por hipótese, se um contribuinte tiver um benefício reduzido e outro contribuinte que seja seu concorrente mantiver o mesmo incentivo por mais tempo que aquele, haverá um enorme prejuízo relativo ao primeiro contribuinte. Em outra hipótese, se ambos contribuintes, já instalados, mantiverem os respectivos incentivos, ainda que por igual tempo, porém, este incentivo deixe de ser ofertado a novos concorrentes do mesmo mercado, assim seria criada uma poderosa barreira à entrada e consequentemente haveria desestímulo a novos investimentos. ${ }^{26}$

Não custa recordar que, em uma situação similar a que se passa no Brasil, a unanimidade também é exigida para regulação básica do imposto sobre valor adicionado (IVA) cobrado na União Europeia. ${ }^{27}$

Vale retornar a análise do processo judicial. Nesse contexto, ao invés de invalidar a decisão tomada pelos entes federativos em observância ao procedimento constitucional previsto, cumpriria ao STF zelar pelo cumprimento do referido acordo, que, em última análise, corresponde ao pleno exercício do federalismo em sua modalidade cooperativa, algo raro de se ver no país.

Essa coalizão dos Estados em torno da remissão de créditos tributários decorrentes de benefícios inconstitucionalmente concedidos no passado encontra justificativa na moralidade dos atos legislativos e na proteção à confiança do contribuinte (arts. $5^{\circ}$, caput, e 37 da CF/88), este último

expresso na exigência de leis claras e densas e o princípio da confiança, traduzido na exigência de leis tendencialmente estáveis ou, pelo menos, não lesivas da previsibilidade e calculabilidade dos cidadãos relativamente aos seus efeitos. ${ }^{28}$

Isso porque as empresas confiaram nos benefícios que foram prometidos e instituídos por lei, cuja constitucionalidade era, pois, presumida. Em face desses atos do Estado, foram realizados investimentos, gerou-se renda, emprego e qualificação da mão de obra, conforme demonstra análise realizada pela Fundação Getúlio Vargas (FGV). ${ }^{29}$

Em relação aos denominados TAREs, por exemplo, a Diretoria de Arrecadação do Distrito Federal ${ }^{30}$ explicitou que, entre 1999 e 2002, houve incremento na receita média mensal da ordem de $\mathrm{R} \$ 2$ milhões, considerando o ano de 2000 contra o de 1999; de R $\$ 3,5$ milhões, no ano de 2001, ante o de 2000; e de R\$ 3,2 milhões, em 2002, em comparação a 2001. Em termos nominais, a receita do Setor Atacadista cresceu cerca de 74\% entre 1999 e 2001. Houve, ainda, crescimento da participação percentual do Setor Atacadista no total da Arrecadação do ICMS nos percentuais de 8,7\% em 1999; 
$8,9 \%$ em 2000; 10,6\% em 2001 e 12,3\% até junho de 2002. Por fim, o volume da receita do Setor Atacadista passou de um patamar de $\mathrm{R} \$ 97$ milhões para $\mathrm{R} \$ 167$ milhões em 2001, chegando a $\mathrm{R} \$ 103$ milhões no acumulado de janeiro a junho de 2002.

Assim, considerando que o STF já chancelou o entendimento de que "razões de segurança jurídica podem obstar à revisão do ato praticado com base na lei declarada inconstitucional", ${ }^{31}$ a concordância unânime dos Estados em conceder remissão aos débitos tributários decorrentes de benefícios unilaterais do passado está em consonância não apenas com os arts. $155, \S 2^{\circ}$, XII, 'g', da CF/88 e $1^{\circ}, 2^{\circ}, \S 2^{\circ}$, e 10 da LC n. $.^{\circ} 24 / 75$, mas com os princípios da confiança e da moralidade (arts. $5^{\circ}$, caput, e $37 \mathrm{da} C F / 88$ ), pois, não fosse assim, seriam apenados exatamente aqueles contribuintes que confiaram no Poder Público, investiram e geraram receitas e ganhos diretos e indiretos - para a sociedade.

\section{SUPERAÇÃO DE INCONSTITUCIONALIDADE FORMAL E DIÁ- LOGO INSTITUCIONAL}

OSTF sempre foi severo e rigoroso ao examinar a constitucionalidade de benefícios fiscais estaduais e do Distrito Federal, principalmente considerando a formalidade prevista no art. $155, \S 2^{\circ}$, XII, 'g', da CF/88. ${ }^{32}$

Com efeito, a prodigalidade de leis estaduais - estimulada por ampla criatividade institucional - tornou a Corte infensa a quaisquer formas de benefício de ICMS concedido sem autorização do convênio, bem como à concessão de isenção, à redução de base de cálculo e à dispensa de pagamento; ${ }^{33}$ redução de alíquota; ${ }^{34}$ crédito presumido; ${ }^{35}$ prazos especiais de pagamento e redução de correção monetária; ${ }^{36}$ cancelamento de notificações fiscais e devolução de valores recolhidos ao erário $;^{37}$ hipóteses expressas de não incidência, ${ }^{38}$ ainda que justificadas em caráter extrafiscal, como estímulo ao emprego de idosos ${ }^{39}$ ou de egressos do sistema penitenciário. ${ }^{40}$

É certo que a reiterada e firme jurisprudência do STF não foi suficiente para solucionar a questão, uma vez que há muitos estados que contam com a demora no ajuizamento e no processamento das ações no âmbito do Supremo a fim de atrair atividades econômicas para onde não há recursos, infraestrutura ou recursos humanos, em síntese, desenvolvimento. ${ }^{41}$ Portanto, a reiterada insistência na aprovação de leis de benefícios fiscais em ICMS sem a necessária aprovação prévia na forma do art. $155, \S 2^{\circ}$, XII, 'g', da CF/88 só existe porque vale a pena, mesmo com a posterior declaração de inconstitucionalidade, com eficácia erga omnes e efeito vinculante, pelo STF.

Por outro lado, flagrantes tentativas de circunscrever a norma constitucional e a decisão do STF, inclusive por meio da repetição de leis inconstitucionais, ${ }^{42}$ tornaram a Corte ainda mais reticente às considerações materiais subjacentes à concessão de benefícios fiscais. 
Nesse contexto de frustração e de desconfiança, é preciso diferenciar com cuidado os casos de esvaziamento das decisões do STF daqueles de seu efetivo cumprimento.

No caso em apreço, o Distrito Federal não se limitou a reiterar a lei declarada inconstitucional, antes buscou a aprovação unânime do CONFAZ, o que elimina a inconstitucionalidade formal da primeira lei. No entanto, não o fez por meio de idêntico benefício fiscal (concessão de crédito tributário de ICMS), mas pela remissão de créditos anteriores.

Ora, a remissão é espécie autônoma de benefício fiscal, prevista no art. 156, IV, do CTN, que, sem dúvida, no âmbito do ICMS, exige a aprovação dos Estados na forma do art. 155, § 2 , XII, 'g', da CF/88.

Evidentemente, a preocupação do Distrito Federal não é de instituir estímulo fiscal para o futuro, mas de solucionar pendência pretérita ocasionada pela declaração de inconstitucionalidade, seja em relação à segurança jurídica, seja quanto à boa-fé dos contribuintes que confiaram na legislação distrital. A tentativa de alcançar fatos anteriores, por si só, não significa desafio à decisão do STF nem ofensa à retroatividade. A rigor, a remissão tributária necessariamente cuida de fatos anteriores.

Não seria surpreendente se a aquiescência obtida junto aos demais estados no CONFAZ fosse restrita justamente aos eventos ocorridos entre a edição da primeira lei e a declaração de inconstitucionalidade proferida pelo STF. A todos interessa pacificar controvérsias pendentes, mas nem sempre os estados estão dispostos a autorizar futuros benefícios fiscais para o Distrito Federal.

A preocupação concreta com a situação de contribuintes atraídos pela norma benéfica pode cumprir a decisão do STF, desde que a nova legislação não incida no mesmo empecilho que acarretou a inconstitucionalidade formal da lei, por óbvio.

É ainda importante destacar que o efeito vinculante das decisões do STF não atinge o Poder Legislativo, nos termos do art. 102,43 por uma razão muito importante: permitir o diálogo institucional ${ }^{44}$ entre Judiciário e Legislativo, de modo que o debate não se encerre simplesmente com uma decisão judicial. Cabe ao Poder Legislativo, em especial ao estadual e ao distrital, como laboratórios da federação, testar outras formas e hipóteses na solução de problemas que afetam a comunidade, sobretudo aquelas relacionadas ao desenvolvimento de cada região.

Frise-se que a preocupação com a segurança jurídica já encontrou amparo na jurisprudência do STF mesmo no caso de leis editadas em desacordo com a exigência do art. 155, § 2º, XII, 'g', da CF/88. Na ADI 429/CE, Rel. Min. Luiz Fux, Pleno, DJe 30.10.2014, o Plenário decidiu modular os efeitos, garantindo a manutenção da inconstitucional isenção de ICMS, por mais 12 meses contados da data de julgamento, quanto a implementos, a veículos e a equipamentos destinados a deficientes físicos, de forma a permitir que seja editado o devido 
convênio, inclusive com efeitos retroativos. Daí que a Proposta de Súmula Vinculante (PSV) n. 69, elaborada pelo Min. Gilmar Mendes, a propósito do assunto, tenha diversas manifestações no sentido da modulação dos seus efeitos.

Logo, a remissão de ICMS, devidamente autorizada pelo CONFAZ, não constitui desafio à orientação do STF, mas verdadeira correção de rumos e de efetivo cumprimento de sua decisão. Afastados os empecilhos formais, cabe ao STF examinar se a solução escolhida pelo Poder Legislativo é materialmente constitucional, considerando a segurança jurídica e a boa-fé dos contribuintes diretamente interessados.

\section{CONCLUSÃO}

Os incentivos fiscais de ICMS, concedidos unilateralmente por determinados Estados e pelo Distrito Federal, constituem causa de conflitos entre as unidades da Federação e de insegurança jurídica entre os contribuintes.

Ao concordarem unanimemente, por intermédio de Convênio do CONFAZ, em conceder remissão a créditos tributários decorrentes da fruição desses benefícios fiscais, os entes federativos buscaram atenuar alguns dos efeitos deletérios decorrentes dessa prática existente no contexto da denominada Guerra Fiscal. Trata-se de um avanço, um exemplo de negociação que dificilmente se tem visto no âmbito da competição fiscal entre os Estados e os que buscam proteger o contribuinte que confiou nos incentivos e na legislação editada por cada ente político e, a partir disso, investiu em localidades que, se não fossem os incentivos, nunca receberiam investimentos produtivos em face da desigualdade regional persistente no país.

Nesse contexto, defende-se que não seriam aplicáveis as decisões proferidas pelo STF na ADI n. ${ }^{\circ} 2.906 / \mathrm{RJ}$ e nos REs n. ${ }^{\text {os }}$ 390.840/MG, 357.950/RS, 358.273/RS, 346.084/PR à hipótese. Isso porque, na referida ADI, a remissão de créditos tributários fora declarada inconstitucional por não ter sido precedida de Convênio do CONFAZ. No processo de repercussão geral, entretanto, a remissão foi concedida pela legislação específica do Distrito Federal, após a edição de Convênio unânime do CONFAZ a autorizá-la. As situações são, dessa forma, diversas.

Também não parece possível aplicar ao caso de repercussão geral o decidido pelo STF nos recursos extraordinários suprarreferidos, pois não está em discussão a possibilidade de repristinar as legislações originárias - já declaradas inconstitucionais - que concederam os incentivos fiscais unilaterais. Na situação em análise, são outras leis, com objetivos diversos e que não pretendem reeditar aqueles mesmos benefícios, mas apenas conceder remissão a determinados créditos tributários.

Além disso, aqueles precedentes julgaram caso de inconstitucionalidade material (alargamento da base de cálculo prevista constitucionalmente para a 
COFINS), ao passo que as leis que editaram os incentivos fiscais no passado foram declaradas inconstitucionais em virtude de vício formal, isto é, por não ter sido obedecido o procedimento previsto para a sua formação, consistente na edição de Convênio do CONFAZ a autorizá-las, já que não há dúvida acerca da competência impositiva dos Estados e do Distrito Federal para legislarem sobre o ICMS. Nesse sentido, e considerando que a inconstitucionalidade formal é sanável, legislação superveniente que tenha obedecido ao procedimento previsto constitucionalmente não poderia ser taxada de inconstitucional em razão de vícios de forma presentes nas legislações anteriores.

Ao contrário, a edição, pelo CONFAZ, de convênios unânimes que permitem a remissão dos créditos de ICMS glosados em função dos incentivos fiscais concedidos, no passado, de forma unilateral, reflete verdadeira atividade de cooperação e de coordenação entre as unidades da Federação. Trata-se de instrumento que possibilita a solução de um dos efeitos perversos da chamada Guerra Fiscal em busca do bem-estar coletivo e em respeito às expectativas dos contribuintes que, a partir daqueles incentivos, instalaram empreendimentos que geraram empregos, receita e renda. Esse tipo de solução negociada no âmbito do Federalismo de Cooperação, longe de ser refutado, deve ser prestigiado pelo Tribunal da Federação. Equacionar, ainda que gradualmente, e pacificar, mas definitivamente, Guerra Fiscal entre os estados brasileiros é uma das tarefas mais prementes para a Federação brasileira. Isso é ainda mais necessário diante da grave crise econômica e fiscal.

No primeiro caso, o País caminha para atravessar a pior recessão de sua história republicada e sua superação exige uma retomada firme e sustentada dos investimentos produtivos. Mas, se, em condições de normalidade econômica, muitos empresários já resistiam a decidir investir diante das incertezas jurídicas em torno da validade dos benefícios do ICMS concedidos de forma generalizada pelos entes federados, quer dizer quando o STF passou a condenar de forma sistemática tais incentivos.

No caso da crise fiscal, ela se revela muito mais forte no caso dos governos estaduais, a ponto de um número cada vez maior atrasar pagamentos de fornecedores, dívidas e, até mesmo, salários, impondo uma busca frenética por aumento de receita e que, por vezes, passa pela suspensão parcial, indireta e velada de incentivos antes concedidos. Mas este é o pior caminho para se enfrentar a Guerra Fiscal porque, ao partir para soluções individuais e desordenadas, é bem possível que se trate diferenciadamente os contribuintes, em especial os que concorrem entre si. Muito pior do que o contribuinte ver seu benefício ser reduzido disfarçadamente é temer ou descobrir que o seu concorrente não passou por isso e conseguiu o benefício anterior.

Além dos temores com a recessão na economia, o contribuinte ainda passa a enfrentar riscos crescentes em sua condição de concorrer no mercado competitivo quando alguns estados passam a "desembarcar" da Guerra Fiscal de forma desordenada, descoordenada e intempestiva. Esse cenário retarda e reduz ainda mais a propensão do empresário para investir em aumento futuro 
da produção, de modo que se dispara um círculo vicioso em que a economia brasileira acaba por recuar cada vez mais.

A gravidade da crise imposta pela conjuntura econômica tão adversa só reforça a tese jurídica aqui desenvolvida, que é cada vez mais premente uma pactuação federativa em torno da Guerra Fiscal, que exige uma solução negociada e consensuada entre todos os estados.

\section{REFERÊNCIAS}

AFONSO, José Roberto et al. A renúncia tributária do ICMS no Brasil. Washington: BID, 2014. Disponível em: <http://goo.gl/AkqTru>.

AFONSO, José R.; SOARES, Julia M.; CASTRO, Kleber. Avaliação da estrutura e o desempenho do sistema tributário brasileiro: livro branco da tributação Brasileira. Washington: BID, 2013. Disponível em: <http://www. iadb.org/wmsfiles/products/publications/documents/37434330.pdf $>$.

ALMEIDA, Vinicius Oliveira de. O Estado de Goiás na guerra fiscal e a justiça distributiva na concepção de John Rawls. Revista Conjuntura Econômica, Goiás, n. 23, p. 12-21, dez. 2012.

AMARAL, Gilberto L. et al. Reflexos e paradigmas da guerra fiscal do ICMS. 2012. Disponível em: <http://bit.ly/UbwwIU>.

ANDRADE, Marcos Alves de. Renúncia de receita face à lei de responsabilidade fiscal. 2003. Disponível em: <http://bit.ly/15ENkSP>.

AQUINO, Jorge Inácio. Benefícios fiscais, guerra fiscal e a reforma tributária no Brasil. 2012. Disponível em: <http://bit.ly/1fA7NOL>.

ARAÚJO, Erika Amorim. Repercussão da guerra fiscal do ICMS nos municípios brasileiros. Banco Interamericano de Desenvolvimento. Instituições para o Desenvolvimento Divisão de Gestão Fiscal e Municipal. IDB-DP-326. Washington: BID, 2014.

ARAÚJO, Guilherme Rocha; VIANA, Thalissa Fernanda Matos. Diferenciação da alíquota de ICMS e a guerra fiscal entre os estados. Disponível em: $<$ http://bit.ly/15ETGSi>.

BARATTO, Gedalva; MACEDO, Mariano de Mattos. Regime tributário do ICMS nas transações interestaduais - harmonização tributária ou autonomia estadual?. Revista Paranaense de Desenvolvimento, Curitiba, n. 113, p. 9-30, jul./dez. 2007.

BERCOVICI, Gilberto. Desigualdades regionais, estado e constituição. São Paulo: Max Limonad, 2003.

. Dilemas do estado federal brasileiro. Porto Alegre: Livraria do Ad-

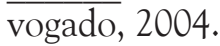


BEVILACQUA, Lucas. Incentivos fiscais de ICMS e desenvolvimento regional. São Paulo, IBDT e Quartier Latin, 2013.

BORGES, José Souto Maior. Sobre as Isenções, Incentivos e Benefícios Fiscais Relativos ao ICMS. Revista Dialética de Direito Tributário, São Paulo, n. 6, p. 69-73, mar. 1996.

BRASIL. Senado Federal. Projeto de Lei Senado n. ${ }^{\circ}$ 130/14. Disponível em: $<$ http://bit.ly/1QjX1Mx>.

BRASIL. Supremo Tribunal Federal. RE n. ${ }^{\circ}$ 851.421/DF. Rel. Min. Marco Aurélio, Plenário Virtual, Dje 01/09/2015.

. AC n. ${ }^{o}$ 3802/DF. Rel. Min. Marco Aurélio, DJe 24/04/2015.

. ADI n. 2.906/RJ. Rel. Min. Marco Aurélio, Dje 29/06/2011.

. RE 390840. Rel. Min. Marco Aurélio, DJ 15/08/2006.

. ADI 56. Rel. Min. Nelson Jobim, Tribunal Pleno, DJ 29/11/2002.

$\overline{09-06-2015 .}$

ACO 2661 MC-Ref. Rel. Min. Celso de Mello, Tribunal Pleno, DJe

. RE 197.917/SP. Rel. Min. Maurício Corrêa, Tribunal Pleno J: $\overline{06} / 06 / 2002$.

CAMPOS, Carlos Alexandre de Azevedo. ADI 3.421: releitura da guerra fiscal do ICMS. In: HORBACH, Beatriz Bastide; FUCK, Luciano Felicio (Org.). O Supremo por seus assessores. São Paulo: Almedina, 2014. p. 223-34.

CANOTILHO, J. J. Gomes. Direito Constitucional e Teoria da Constituição. 3. ed. Portugal: Almedina, 1999.

CARVALHO, Ivo César Barreto de. Regime Jurídico dos incentivos fiscais. In: MACHADO, Hugo de Brito (Coord.). Regime jurídico dos incentivos fiscais. São Paulo, Malheiros editores, 2015. p. 267-268.

CARVALHO, Paulo de Barros; MARTINS, Ives Gandra da Silva. Guerra Fiscal: reflexões sobre a concessão de benefícios no âmbito do ICMS. São Paulo, Noeses, 2012. p. 22.

CONTI, José Maurício. Federalismo Fiscal e Fundos de Participação. São Paulo: Juares de Oliveira, 2001.

COSTA, Alcides Jorge. ICM na Constituição e na Lei Complementar. São Paulo: Resenha Tributária, 1978. p. 125.

DE MELLO, L. The brazilian tax war: the case of value-added tax competition among the states. OECD Economics Department Working Papers, France, n. 544, p. 27, 2007.

EUROPEAN COMMISSION. EU Tax Policy Strategy. Brussels: European Commssion, 2001. Disponível em: <http://bit.ly/OJODGr>. 
FERREIRA, Sérgio Guimarães; VARSANO, Ricardo; AFONSO, José Roberto. Inter-jurisdictional Fiscal Competition: a review of the literature and policy recomendations. Political Economy, v. 25, n. 33, p. 295-313, 2005. Disponível em: <http://bit.ly/1VOuMY1>.

FGV. Impactos Socioeconômicos da Suspensão de Incentivos Fiscais. Produto 2 A - Relatório Final (Impactos Socioeconômicos 1 dos Incentivos Fiscais Estaduais). Rio de Janeiro: Federação das Indústrias do Estado de Goiás - FIEG, 2011.

HORTA, Raul Machado. A autonomia dos estados membros no direito constitucional brasileiro. Belo Horizonte: [s.n.], 1964.

KAUFMANN, Roberta Fragoso Menezes. Considerações sobre a Arguição de Descumprimento de Preceito Fundamental n. 198 e sobre a constitucionalidade do exercício da função extrafiscal de benefícios de ICMS por legislações estaduais sem prévio convênio autorizativo do CONFAZ. Ausência de guerra fiscal. In: CONGRESSO NACIONAL DOS PROCURADORES DE ESTADO, 39., 2013, Brasília. Anais... Brasília: [s.n.], 2013. p. 16.

MARTINS, Ives Gandra da Silva. Isenções, Incentivos e Benefícios Fiscais no ICMS em face da denominada guerra fiscal entre Estados. In: MACHADO, Hugo de Brito (Coord.). Regime jurídico dos incentivos fiscais. Malheiros: São Paulo, 2015. p. 232.

MELlO, Gustavo Miguez de; SIMÕES, Luiz Carlos Marques. Regime jurídico dos incentivos fiscais. In: ROCHA, Valdir de Oliveira (Coord.). Grandes questões atuais de direito tributário. São Paulo: Dialética, 2011. v. 15. p. 129.

MENDES, Gilmar Ferreira; COELHO, Inocêncio Mártires; BRANCO, Paulo Gustavo Gonet. Curso de direito constitucional. São Paulo: Saraiva, 2011.

MENDES, Gilmar Ferreira; CAMPOS, Cesar Cunha (Org.). Federação e guerra fiscal. São Paulo: FGV Projetos, 2011. v. 3.

SILVA, José Afonso da. Federalismo e autonomias no estado brasileiro: federalismo nominal e federalismo de regiões. In: SIMPOSIUM INTERNACIONAL DE DERECHO CONSTITUCIONAL AUTONÓMICO, 1. Espanha: Generalitat Valenciana, 1985.

SILVA, José Afonso. Curso de Direito Constitucional Positivo. 25. ed. São Paulo: Malheiros, 2005.

SCAFF, Fernado Facury. A inconstitucional unanimidade do Confaz e o surpreendente Convênio 70. Disponível em: <http://www.conjur.com.br $>$. Acesso em: 20 out. 2015.

VARSANO, Ricardo. A guerra fiscal do ICMS: quem ganha e quem perde. Planejamento e Políticas Públicas, Brasília, n. 15, p. 3-19, jun. 1997. Disponível em: <http://bit.ly/19EDiAQ>. 
1 Incentivos fiscais são renúncias de receitas públicas materializadas por instrumentos de política fiscal/ tributária, tais como anistia, remissão, crédito presumido, isenção, redução da base de cálculo, moratória, parcelamento, reembolso tributário, subsídios financeiros ou creditícios vinculados a determinado tributo. Para maiores informações, inclusive sobre o percentual da renúncia de ICMS de cada Estado da Federação em função do PIB, da arrecadação desse imposto e dos investimentos realizados, vide AFONSO, J.R. et alli., 2014.

2 Exemplificativamente, segue o disposto no Convênio n. ${ }^{\circ}$. 86/2011, reproduzido, em linhas gerais, pelo Convênio n. ${ }^{\circ}$. 84/2011:

Cláusula primeira. Fica suspensa a exigibilidade dos créditos tributários de ICMS resultantes da diferença entre o regime normal de apuração e o tratamento tributário decorrente da opção do contribuinte pelo regime de apuração do ICMS previsto na Lei Distrital n. ${ }^{\circ}$ 2.381, de 20 de maio de 1999, revogada pela Lei Distrital n. ${ }^{\circ} 4.100$, de 29 de fevereiro de 2008, que também extinguiu os Termos de Acordo de Regime Especial decorrentes da lei revogada (...)

Parágrafo único. Fica concedida, desde que atendidos os requisitos da cláusula terceira deste convênio, remissão dos créditos tributários suspensos na forma do caput, nos termos finais de sua suspensão.

(...)

Cláusula terceira. O Distrito Federal, nos termos deste convênio e a partir de sua celebração, acorda em não conceder ou prorrogar incentivos ou benefícios fiscais vinculados ao ICMS, em operações interestaduais, concedidos com base na norma referida na cláusula primeira, ressalvada a concessão ou prorrogação na forma prevista da Lei Complementar n. ${ }^{\circ}$ 24, de 7 de janeiro de 1975. (sem grifos no original)

3 Vale reproduzir o previsto na Constituição Federal.

Art. 155. Compete aos Estados e ao Distrito Federal instituir impostos sobre:

II - operações relativas à circulação de mercadorias e sobre prestações de serviços de transporte interestadual e intermunicipal e de comunicação, ainda que as operações e as prestações se iniciem no exterior; (Redação dada pela Emenda Constitucional n. ${ }^{\circ} 3$, de 1993)

$\S 2^{\circ} \mathrm{O}$ imposto previsto no inciso II atenderá ao seguinte:

XII - cabe à lei complementar:

g) regular a forma como, mediante deliberação dos Estados e do Distrito Federal, isenções, incentivos e benefícios fiscais serão concedidos e revogados.

Art. $1^{\circ}$ - As isenções do imposto sobre operações relativas à circulação de mercadorias serão concedidas ou revogadas nos termos de convênios celebrados e ratificados pelos Estados e pelo Distrito Federal, segundo esta Lei.

Art. $2^{\circ}$ - Os convênios a que alude o art. $1^{\circ}$, serão celebrados em reuniões para as quais tenham sido convocados representantes de todos os Estados e do Distrito Federal, sob a presidência de representantes do Governo federal.

$\S 2^{\circ}$ - A concessão de benefícios dependerá sempre de decisão unânime dos Estados representados; a sua revogação total ou parcial dependerá de aprovação de quatro quintos, pelo menos, dos representantes presentes.

4 Manifestação na repercussão geral no RE 851421.

5 Segundo ARAUJO; VIANA, 2012, "A guerra fiscal se caracteriza por concessões unilaterais, ao arrepio da Lei, de benefícios e incentivos fiscais para atrair investimentos. Esses incentivos são dados no âmbito do ICMS, imposto estadual que tributa a circulação de mercadorias e determinados serviços. Entre as diversas vertentes de benefícios, o financiamento em longo prazo do pagamento do ICMS é mais largamente empregado. O objetivo é facilitar, ao máximo, a instalação da empresa. Ocorre que, no intuito de conceder reduções e/ou isenções nas alíquotas de ICMS, os Estados e o Distrito Federal devem firmar, por expressa disposição legal, convênios entre si. Esses convênios devem ser firmados no âmbito do CONFAZ - Conselho Nacional de Política Fazendária, constituído por membros do Governo Federal e secretários de Fazenda de cada membro federativo. O CONFAZ foi instituído por meio da Lei Complementar n. 24, de 07 de outubro de 1975, a qual determina, ainda, que a concessão de um benefício depende, necessariamente, da decisão unânime dos Estados representados e estabelece penalidades em casos de descumprimento. A guerra fiscal corre, simplesmente, à revelia da LC n. 24/75 e da própria Constituição da República (art. 155, § 2 , XII, "g”). Qualquer isenção, incentivo, redução de alíquota ou de base de cálculo, crédito presumido, dispensa de pagamento ou outro benefício fiscal relativo ao ICMS, concedido sem prévia aprovação em convênio celebrado no âmbito do CONFAZ, é inconstitucional. Toda essa incongruência do Sistema Tributário brasileiro poderia, facilmente, ser solucionada com a simples obediência à Lei Complementar n. ${ }^{\circ}$ 24/75, embora se reconheça que existe, atualmente, um empenho institucional no sentido de evitar que os Estados continuem a conceder benefícios relativos 
ao ICMS unilateralmente, prejudicando o equilíbrio tributário nacional."

Conforme apontam AFONSO, SOARES e CASTRO (2013), a competição fiscal ocorre no Brasil desde 1920, passando pela criação do ICM, em 1965, e do CONFAZ, em 1970, sendo este último um órgão destinado a controlar e a coordenar as disputas entre os Estados no que respeita aos incentivos fiscais ancorados no ICMS.

6 Ação Cautelar (AC) n. ‥ 3802/DF, Relator Ministro Marco Aurélio, DJe 24/04/2015.

7 Idem.

8 Pela ótica da avaliação econômica da Guerra Fiscal, especificamente para revisitar a literatura da concorrência fiscal, que é um fenômeno internacional, ver FERREIRA, VARSANO e AFONSO (2005). Além disso, destaque-se que a Guerra Fiscal produz efeitos econômicos não apenas sobre os Estados que competem entre si, mas repercute também sobre os Municípios no que se refere à repartição constitucional da receita de ICMS (cota-parte). A propósito, confira: ARAÚJO, 2014.

9 Idem.

10 ADIN n. ${ }^{\circ}$ 2.906/RJ, Rel. Min. Marco Aurélio, Dje 29/6/2011.

11 RE 390840, Rel. Min. Marco Aurélio, DJ 15/08/2006.

12 CANOTILHO, J. J. Gomes. Direito Constitucional e Teoria da Constituição. 3. ed. Portugal: Almedina, 1999.

13 MENDES, Gilmar Ferreira; COELHO, Inocêncio Mártires; BRANCO, Paulo Gustavo Gonet. Curso de direito constitucional. São Paulo: Saraiva, 2011.

14 "Essa incompatibilidade vertical de normas inferiores (leis, decretos etc.) com a constituição é o que, tecnicamente, se chama inconstitucionalidade das leis ou dos atos do Poder Público, e que se manifesta sob dois aspectos: (a) formalmente, quando tais normas são formadas por autoridades incompetentes ou em desacordo com formalidades ou procedimentos estabelecidos pela constituição; (b) materialmente, quando o conteúdo de tais leis ou atos contrairá preceito ou princípio da constituição." (SILVA, 1999)

15 E a inconstitucionalidade formal pode ser sanada, a partir da obediência ao procedimento constitucionalmente previsto. Na ADI 56 (Relator Ministro NELSON JOBIM, Tribunal Pleno, julgado em 03/10/2002, DJ 29/11/2002), por exemplo, o STF julgou parcialmente prejudicada a ação direta, pois entendeu que "O vício de iniciativa foi sanado em face da apresentação de Projeto de Lei, por parte do Executivo, de idêntica matéria."

16 CONTI, José Maurício. Federalismo Fiscal e Fundos de Participação. São Paulo: Juares de Oliveira, 2001.

17 "a relação entre federalismo e cooperação surge na etimologia da palavra federal, que deriva de foedus amicitae, pacto, ajuste, convenção, tratado, e entra na composição de laços de amizade, foedus amicitae, ou de união matrimonial, foedus thalamni" (HORTA, 1964)

18 SILVA, José Afonso da. Federalismo e autonomias no estado brasileiro: federalismo nominal e federalismo de regiões. In: SIMPOSIUM INTERNACIONAL DE DERECHO CONSTITUCIONAL AUTONÓMICO, 1. Espanha: Generalitat Valenciana, 1985.

19 BERCOVICI, 2000.

20 "A Constituição da República confere ao Supremo Tribunal Federal a posição eminente de Tribunal da Federação (CF, art. 102, I, "f'), atribuindo a esta Corte, em tal condição institucional, o poder de dirimir controvérsias que, ao irromperem no seio do Estado Federal, culminam, perigosamente, por antagonizar as unidades que compõem a Federação. Essa magna função jurídico-institucional da Suprema Corte impõe-lhe o gravíssimo dever de velar pela intangibilidade do vínculo federativo e de zelar pelo equilíbrio harmonioso das relações políticas entre as pessoas estatais que integram a Federação brasileira. A aplicabilidade da norma inscrita no art. 102, I, "f", da Constituição estende-se aos litígios cuja potencialidade ofensiva revela-se apta a vulnerar os valores que informam o princípio fundamental que rege, em nosso ordenamento jurídico, o pacto da Federação". (ACO 2661 MC-Ref, Relator(a): Min. CELSO DE MELLO, Tribunal Pleno, julgado em 13/05/2015, PROCESSO ELETRÔNICO DJe-109 DIVULG 08-06-2015 PUBLIC 09-06-2015)

21 Vide sobre o tema: SILVA, 2005.

22 HORTA, Raul Machado. A autonomia dos estados membros no direito constitucional brasileiro. Belo Horizonte: [s.n.], 1964.

23 PLS n..$^{\circ}$ 130/14: "Dispõe sobre convênio que permita aos Estados e ao Distrito Federal deliberar sobre a remissão dos créditos tributários, constituídos ou não, decorrentes de isenções, incentivos e benefícios fiscais ou financeiro-fiscais instituídos em desacordo com o disposto no art. $155, \S 2^{\circ}$, inciso XII, alínea 'g', da Constituição Federal e a reinstituição das respectivas isenções, incentivos e benefícios fiscais ou financeiro-fiscais". 
24 Segundo o art. 23, § 6 $6^{\circ}$, da CF/67: "As isenções do impôsto sôbre operações relativas à circulação de mercadorias serão concedidas ou revogadas nos têrmos fixados em convênios, celebrados e ratificados pelos Estados, segundo o disposto em lei complementar". Sobre o caráter impositivo dos Convênios, vide: RE 96.545, Min. Moreira Alves, J: 01/09/82. No mesmo sentido, COSTA (1978), comentando o art. 23, §6 ${ }^{\circ}$, da Constituição de 1967/69, afirmou que, "mesmo na ausência da lei complementar nele referida, os Estados não podiam conceder isenções a não ser através de convênio." ICM na Constituição e na lei complementar" (p. 125).

25 Há três posições diferentes sobre a constitucionalidade do quorum da unanimidade no CONFAZ. A primeira corrente o considera inconstitucional (KAUFMANN, 2013; SCAFF, 2015; SILVEIRA e SCAFF, 2015; MELLO E SIMÕES, 2011; CARVALHO, 2015; CARVALHO, 2012). A segunda posição o considera decorrência direta da constituição (MARTINS, 2015; COSTA, 1978). A terceira corrente, que nos parece a mais adequada, considera constitucional o quorum da unanimidade, embora admita a possibilidade de modificá-lo na via legislativa própria e desde que haja consenso político para tanto (VIANA e NETO, 2015).

26 Sobre os aspectos conceituais e teóricos dos incentivos e os efeitos econômicos da tributação sobre a alocação de recursos nos negócios, vide: FERREIRA, VARSANO E AFONSO, 2005.

27 A exigência de unanimidade está contemplada no art. 113, em meio ao capítulo sobre tax provisions, do Tratado da União Europeia. Disponível em: < http://bit.ly/OJOwL2>. Em um cenário similar ao brasileiro, aquela União adota um imposto sobre valor adicionado (IVA), e o papel de cada país que integra tal comunidade é próximo ao de cada estado em relação ao ICMS brasileiro - vale ver sua estratégia de política fiscal em EUROPEAN COMMISSION, 2001 - ou ainda, em sua página de seu portal na internet disponível em: < http://bit.ly/OJODGr $\geq$. VARSANO comenta: “(...) que a European Comission (que é um órgão assessor da UE) vem propondo já há algum tempo maioria qualificada para assuntos tributários (para facilitar a harmonização), mas a proposta tem sido rejeitada por países membros e, em particular, não foi incluída no Tratado de Lisboa que vai estar em vigor a partir de 2014."

28 CANOTILHO, J. J. Gomes. Direito Constitucional e Teoria da Constituição. 3. ed. Portugal: Almedina, 1999.

29 A FGV demonstrou que empreendimentos instalados e operados graças a incentivos de ICMS produzem efeitos multiplicadores não só da arrecadação, como também do PIB e do emprego. Um dos projetos analisados pela FGV está instalado no Distrito Federal e, sozinho, viabilizou cerca de 1,2\% da sua arrecadação tributária, no ano de 2010 (p. 25). (FGV - Impactos Socioeconômicos da Suspensão de Incentivos Fiscais, Rio de janeiro, 16 de setembro de 2011)

Para uma análise empírica sobre a concorrência horizontal entre os Estados em torno do ICMS, no período de 1985 a 2001, vide: DE MELLO, 2007.

30 Dados extraídos das informações prestadas pelo Distrito Federal no Processo n. . . 2003011008145-4 (0008145-71.2003.807.0001 - Tribunal de Justiça do Distrito Federal - AREsp 351.884 - íntegra eletrônica obtida no sítio eletrônico do Superior Tribunal de Justiça).

31 RE 197.917/SP. Rel. Min. Maurício Corrêa, J: 06/06/2002, Voto Ministro Gilmar Mendes.

32 Com menos de um ano de vigência da CF/1988, em 27.9.1989, o STF concedeu medida cautelar na ADI-MC 84/MG, Rel. Min. Sydney Sanches, Pleno, DJ 6.10.1995, para suspender normas da Constituição do Estado de Minas Gerais que concediam isenção de ICMS em hipóteses não autorizadas por convênios. A quantidade de ações diretas sobre o assunto é tão expressiva que o STF já organizou mutirões para julgamento conjunto de normas estaduais, como ocorrido em $1^{\circ} .6 .2011$, em que 14 ações diretas de inconstitucionalidade foram apreciadas em conjunto (Informativo 629/STF). A propósito, cf. MENDES, 2011; BORGES, 1996. E CAMPOS, 2014.

33 ADI 2.548/PR, Rel. Min. Gilmar Mendes, Pleno, DJ 15.6.2007.

34 ADI 3.664/RJ, Rel. Min. Cezar Peluso, Pleno, DJ 21.9.2011.

35 ADI 1.587/DF, Rel. Min. Octavio Gallotti, Pleno, DJ 7.12.2000.

36 ADI-MC 1.179/SP, Rel. Min. Marco Aurélio, Pleno, DJ 12.4.1996.

37 ADI 2.345/SC, Rel. Min. Cezar Peluso, Pleno, DJe 5.8.2011.

38 ADI 286/RO, Rel. Min. Maurício Corrêa, Pleno, DJ 30.8.2002.

39 ADI 1.276/SP, Rel. Min. Ellen Gracie, Pleno, DJ 29.11.2002.

40 ADI 3.809/ES, Rel. Min. Eros Grau, Pleno, DJ 14.9.2007.

41 Cf. o depoimento do ex-governador do Estado de Mato Grosso, Blairo Maggi,. In: MENDES, Gilmar Ferreira \& CAMPOS, Cesar Cunha (org.). Federação e Guerra Fiscal. vol. 3. São Paulo: FGV Projetos, 2011. p. 41-45. 
42 A propósito, cf. a ADI-MC 2.021/SP, Rel. Min. Maurício Corrêa, Pleno, DJ 18.5.2001. Na oportunidade, o Estado de São Paulo substituiu a Lei paulista 10.231 de 12.3.1999, antes que o STF concluísse o julgamento da respectiva ação direta de inconstitucionalidade (ADI 1.978-SP, Rel. Min. Nelson Jobim), pela Lei paulista 10.327, de 15.6.1999. Ressalte-se que essa segunda lei paulista previa vigência de apenas três meses, contando com as limitações da Suprema Corte de apreciar, em tão curto tempo, a questão constitucional.

43 Art. 102, §2, $\mathrm{CF} / 88$ : "As decisões definitivas de mérito, proferidas pelo Supremo Tribunal Federal, nas ações diretas de inconstitucionalidade e nas ações declaratória de constitucionalidade produzirão eficácia contra todos e efeito vinculante, relativamente aos demais órgãos do Poder Judiciário e à administração pública direta e indireta, nas esferas federal, estadual e municipal" (grifo nosso).

44 A propósito, cf. VICTOR, Sérgio Antônio Ferreira. Diálogo Institucional e Controle de Constitucionalidade: debate entre o STF e o Congresso Nacional. São Paulo: Saraiva, 2015.

\title{
THE CONSTITUTIONALITY OF AGREEMENTS CELEBRATED AMONG STATES ON TAX INCENTIVES
}

\begin{abstract}
The Supreme Federal Court will judge whether it is possible to pardon tax credits arising from incentives granted unilaterally by the states and the Federal District, if CONFAZ subsequently agreed on the matter. Given that formal unconstitutionalities may be remedied, any supervening legislation that followed constitutional procedure could not be labeled as unconstitutional due to procedural defects present in previous legislation. This is not about modulating the effectiveness of any laws that have previously been deemed unconstitutional. The most recent pieces of legislation, based on the principle of separation of powers and on the federal pact, deal with another matter, i.e., the legal treatment of tax claims resulting from the use of tax benefits declared as unconstitutional. The prohibition of the aforementioned remission would withdraw from the states that make up the Federation one of the instruments that, in the context of federalism, coordination and cooperation, allows for negotiation around problems concerning Tax War, in search of the collective well-being, while respecting the expectations of taxpayers.
\end{abstract}

Keywords: Supreme Federal Court. Tax war. Remission. CONFAZ. Federal Pact. Federalism. Cooperation. Legal certainty.

Submetido: 7 mar. 2016

Aprovado: 13 maio 2016 